ARTICLE

https://doi.org/10.1038/s41467-021-25726-w

\title{
Adjacent single-atom irons boosting molecular oxygen activation on $\mathrm{MnO}_{2}$
}

Huayu Gu${ }^{1}$, Xiao Liu ${ }^{1 凶}$, Xiufan Liu ${ }^{1}$, Cancan Ling ${ }^{1}$, Kai Wei ${ }^{1}$, Guangming Zhan ${ }^{1}$, Yanbing Guo ${ }^{1}$ \& Lizhi Zhang (i) ${ }^{1 凶}$

Efficient molecular oxygen activation is crucial for catalytic oxidation reaction, but highly depends on the construction of active sites. In this study, we demonstrate that dual adjacent Fe atoms anchored on $\mathrm{MnO}_{2}$ can assemble into a diatomic site, also called as $\mathrm{MnO}_{2}$-hosted Fe dimer, which activates molecular oxygen to form an active intermediate species $\mathrm{Fe}(\mathrm{O}=\mathrm{O}) \mathrm{Fe}$ for highly efficient $\mathrm{CO}$ oxidation. These adjacent single-atom Fe sites exhibit a stronger $\mathrm{O}_{2}$ activation performance than the conventional surface oxygen vacancy activation sites. This work sheds light on molecular oxygen activation mechanisms of transition metal oxides and provides an efficient pathway to activate molecular oxygen by constructing new active sites through single atom technology.

\footnotetext{
${ }^{1}$ Key Laboratory of Pesticide \& Chemical Biology of Ministry of Education, College of Chemistry, Central China Normal University, 430079 Wuhan, P. R. China.

凶email: liuxiao71@mail.ccnu.edu.cn; zhanglz@mail.ccnu.edu.cn
} 
$\mathrm{M}$ olecular oxygen activation, a continuous process of adsorption and dissociation of $\mathrm{O}_{2}$ on the catalyst surface (Supplementary Fig. 1), is a key step in catalytic reactions ${ }^{1}$, including the synthesis of organic compounds, catalytic combustion of volatile organic compounds (VOCs), oxygen reduction reaction (ORR) in fuel cells and so $\mathrm{on}^{2-4}$. The construction of oxygen vacancy, as an anion defect, is widely studied, which could improve the ability of molecular oxygen activation by electron transfer from the surface to the adsorbent ${ }^{5,6}$. However, high concentration of oxygen in air or high temperature will inevitably lead to the refilling of oxygen vacancy ${ }^{7}$. Although the production of surface unsaturated oxygen atoms with dangling bonds by surface chemical modification is a pathway to provide reactive oxygen species, the limited surface oxygen contents hinder the continuous reaction due to the inadequate supply of reactive oxygen species ${ }^{8}$. The use of metalloenzymes to generate different metal-oxo species can also trigger many oxidation reactions ${ }^{9}$, but suffers from their high cost. Therefore, facile and efficient dioxygen activation is still a bottleneck for catalytic oxidation reaction ${ }^{4}$.

The application of single atom technology in molecular oxygen activation paves a new pathway ${ }^{10}$. For example, $\mathrm{Wu}$ et al. reported that negatively charged $\mathrm{Au}$ atoms could activate molecular oxygen by regulating the depletion of adjacent oxygen atoms to produce defect oxygen sites in single-atom catalyst $\mathrm{Au} /$ $\mathrm{CuO}^{11}$. Tang and coworkers proposed that $\mathrm{Na}$ atoms could provide electrons to the catalyst surface, and thus endowed lattice oxygen with higher electron density to more easily participate in the catalytic reaction ${ }^{12}$. These examples revealed that single atoms promoted molecular oxygen activation via activating surface or lattice oxygen of metal oxides. However, it is still unknown whether the single atoms on transition metal oxides are directly involved in molecular oxygen activation process. Meanwhile, the difference in activation mechanisms between single atom/transition metal oxide and conventional surface oxygen vacancies based on transition metal oxide catalysts is also unclear ${ }^{13}$.

To tackle these two issues, hereby, we anchored single Fe atoms on $\mathrm{MnO}_{2}\left(\mathrm{Fe} / \mathrm{MnO}_{2}\right)$ through an oxalate-chelation-assisted hydrothermal method. Compared with conventional oxygen vacancies in $\mathrm{MnO}_{2}$, two adjacent single-atom Fe sites of $\mathrm{Fe} / \mathrm{MnO}_{2}$ are more benefit to activate oxygen molecules immediately by forming $\mathrm{Fe}(\mathrm{O}=\mathrm{O}) \mathrm{Fe}$ active species. From a molecular level, pendant oxygen atom from $\mathrm{Fe}(\mathrm{O}=\mathrm{O}) \mathrm{Fe}$ active species with endon mode was endowed weak bond strength and charge localization to participate in the reaction with lower activation barrier than $\mathrm{O}_{2}$ activated in oxygen vacancy of pure $\mathrm{MnO}_{2}$. The elucidation of two adjacent single-atom active sites enables further opportunities for the inert molecular activation.

\section{Results}

Chemical structure characterization. We selected $\mathrm{Fe} / \mathrm{MnO}_{2}$ with $0.25 \%$ theoretical $\mathrm{Fe}$ content for systematic characterization. All the characteristic X-ray powder diffraction (XRD) peaks of Fe/ $\mathrm{MnO}_{2}$ well matched the standard card (JCPDS 44-0141) without additional impurity peaks (Supplementary Fig. 2) ${ }^{14}$. The highangle annular dark-field scanning transmission electron microscope (HAADF-STEM) images of $\mathrm{Fe} / \mathrm{MnO}_{2}$ revealed (010) plane was the main exposed surface (Fig. 1a), which was used in the following calculation and simulation, and no cluster appeared on the catalyst surface (Fig. 1b). The energy-dispersive X-ray spectroscopy (EDXS) mapping suggested even distribution of Fe, Mn and $\mathrm{O}$ elements on the catalyst surface (Fig. 1c). X-ray absorption near edge structure (XANES) and extended X-ray absorption fine structure (EXAFS) spectra of Fe (Fig. 1d, e and Supplementary Fig. 3) displayed that Fe was uniformly distributed on the surface of $\mathrm{MnO}_{2}$ but not in clusters. Supplementary Fig. 4 was XANES and EXAFS spectra of $\mathrm{Mn}$. Regarding to the $\mathrm{Mn}-\mathrm{O}$ characteristic peak at $1.52 \AA, \mathrm{Fe} / \mathrm{MnO}_{2}$ with lower $\mathrm{Mn}-\mathrm{O}$ intensity was ascribed to either the substitution of $\mathrm{Mn}$ or the formation of more oxygen defects. Compared with $\mathrm{MnO}_{2}$, the $\mathrm{Mn}-\mathrm{O}$ bond length in $\mathrm{Fe} /$ $\mathrm{MnO}_{2}$ did change, indicating that Fe may not enter the interior of the bulk to change the coordination environment of $\mathrm{Mn}$ (also observed in Supplementary Fig. 4b). Referring to the Fe K-edge EXAFS spectra, the length of the $\mathrm{Fe}-(\mathrm{O})-\mathrm{Mn}$ bond in the second shell was consistent with the appearance of the $\mathrm{Mn}-(\mathrm{O})-\mathrm{Mn}$ bond, illustrating that $\mathrm{Fe}$ was located at the site of $\mathrm{Mn}$, but had negligible effect on Mn. Similar results were obtained in the study of Smith et al. ${ }^{15}$. According to the results of wavelet transform (Supplementary Fig. 5), the coordination environment of $\mathrm{Fe}$ element in $\mathrm{Fe} / \mathrm{MnO}_{2}$ was obviously different from that of reference sample $\mathrm{Fe}_{2} \mathrm{O}_{3}$, especially in the second coordination layer. We also compared the Fe $3 d$ XPS spectra of $\mathrm{Fe}_{2} \mathrm{O}_{3}$ and $\mathrm{Fe} / \mathrm{MnO}_{2}$ (Supplementary Fig. 6), and found that the characteristic peak of $\mathrm{Fe} / \mathrm{MnO}_{2}$ had lower binding energy $(710.6 \mathrm{eV})$ than that $(711.4 \mathrm{eV})$ of $\mathrm{Fe}_{2} \mathrm{O}_{3}$. Meanwhile, Bader charge calculation results revealed that $\mathrm{Fe}$ on $\mathrm{Fe} / \mathrm{MnO}_{2}$ possessed more electrons than that of $\mathrm{Fe}_{2} \mathrm{O}_{3}$, consistent with the results of XANES absorption (Fig. 1d). Therefore, the distribution of Fe in the form of $\mathrm{Fe}_{2} \mathrm{O}_{3}$ on the catalyst surface can be excluded.

Catalytic activity test. High-efficiency $\mathrm{CO}$ oxidation is of great significance in automotive exhaust purification and the antitoxicity improvement of proton exchange membrane fuel cells $^{16,17}$. Thereby, CO oxidation was taken as a probe reaction to check molecular oxygen activation performance of $\mathrm{Fe} / \mathrm{MnO}_{2}$ and $\mathrm{MnO}_{2}$. Among the six $\mathrm{Fe}$ atoms anchored $\mathrm{MnO}_{2}$ samples, $\mathrm{Fe} /$ $\mathrm{MnO}_{2}$ with $0.25 \%$ theoretical $\mathrm{Fe}$ content achieved the highest catalytic activity under the conditions of $1 \% \mathrm{CO}, 4 \% \mathrm{O}_{2}$ and argon as equilibrium gas (Supplementary Fig. $7 \mathrm{a}$ ). $\mathrm{Fe} / \mathrm{MnO}_{2}$ could realize $100 \%$ conversion of $\mathrm{CO}$ at $80^{\circ} \mathrm{C}$, much better than $\mathrm{MnO}_{2}$ of $100 \%$ $\mathrm{CO}$ conversion at $120^{\circ} \mathrm{C}$ (Fig. 2a). Meanwhile, we calculated the specific activity $\left(R_{T 50}\right)$ of $0.25 \% \mathrm{Fe} / \mathrm{MnO}_{2}$ according to the calculation formula (10) and the value was $310 \mathrm{~mol}_{\mathrm{CO}} \mathrm{h}^{-1} \mathrm{~mol}_{\mathrm{Fe}}{ }^{-1}$ with $T_{50}$ at $47^{\circ} \mathrm{C}$, higher than those of most platinum group metal (PGM) catalysts ${ }^{18}$. Impressively, $\mathrm{Fe} / \mathrm{MnO}_{2}$ maintained stable catalytic activity at $80^{\circ} \mathrm{C}$ for $50 \mathrm{~h}$ (Supplementary Fig. 7b), and robustly resisted the transformation between humid and dry atmospheres (Supplementary Fig. 7c). In contrast, $\mathrm{MnO}_{2}$ seriously suffered from water vapor poisoning with a gradually decreasing conversion rate. Meanwhile, higher surface area normalized catalytic activity of $\mathrm{Fe} / \mathrm{MnO}_{2}$ ruled out the contribution of surface areas to its enhanced activity (Supplementary Figs. 8 and 9) ${ }^{19}$.

To further explore the catalytic process, the Arrhenius plots of $\mathrm{Fe} / \mathrm{MnO}_{2}$ and $\mathrm{MnO}_{2}$ were obtained (inset in Fig. 2a). The apparent activation energy $\left(E_{\mathrm{a}}, 33.7 \mathrm{~kJ} \mathrm{~mol}{ }^{-1}\right)$ of $\mathrm{Fe} / \mathrm{MnO}_{2}$ was much lower than that $\left(70.1 \mathrm{~kJ} \mathrm{~mol}^{-1}\right)$ of $\mathrm{MnO}_{2}$, indicating a lower $\mathrm{CO}$ oxidation activation barrier of $\mathrm{Fe} / \mathrm{MnO}_{2}$ and different $\mathrm{CO}$ oxidation mechanisms of $\mathrm{Fe} / \mathrm{MnO}_{2}$ and $\mathrm{MnO}_{2}$. Subsequently, we investigated the effects of partial pressures of $\mathrm{CO}$ and $\mathrm{O}_{2}$ on turnover frequence (TOF) in the low-temperature region (Fig. $2 \mathrm{~b}$ and c; Supplementary Fig. 10). The $\mathrm{CO}$ and $\mathrm{O}_{2}$ reaction orders (0.01 and 0.35 ) of $\mathrm{Fe} / \mathrm{MnO}_{2}$ were significantly lower than those (0.09 and 0.61 ) of $\mathrm{MnO}_{2}$. The higher reaction order of $\mathrm{O}_{2}$ than CO illustrated that the $\mathrm{O}_{2}$ activation was a key step, consistent with the previously reported results ${ }^{20,21}$. Obviously, $\mathrm{Fe} / \mathrm{MnO}_{2}-$ activated molecular oxygen more easily than $\mathrm{MnO}_{2}$, accounting for its better $\mathrm{CO}$ oxidation catalytic activity.

Detection of active species. We thus distinguished the oxygen species generated during molecular oxygen activation by $\mathrm{O}_{2}-\mathrm{TPD}$ 
(a)

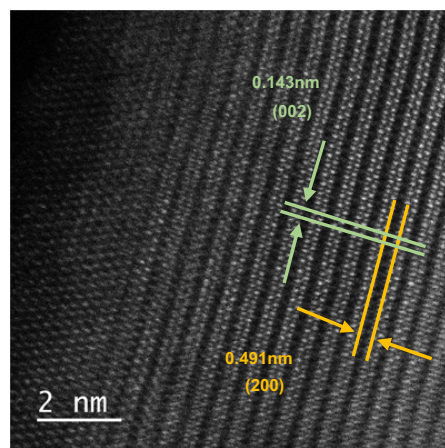

(d)

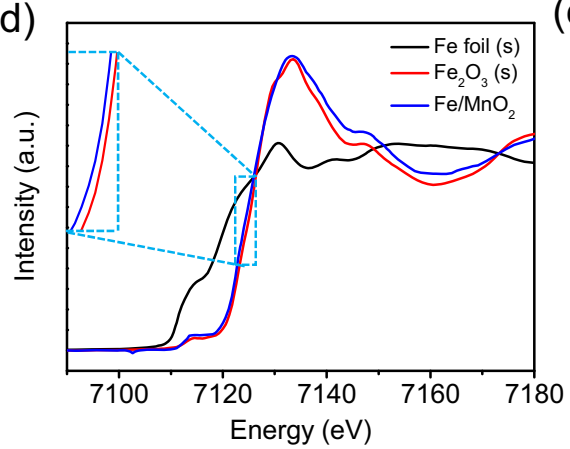

(b)

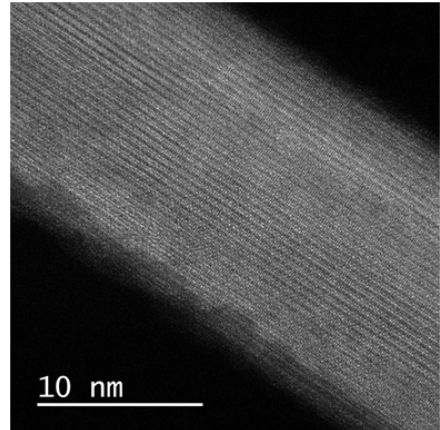

(c)

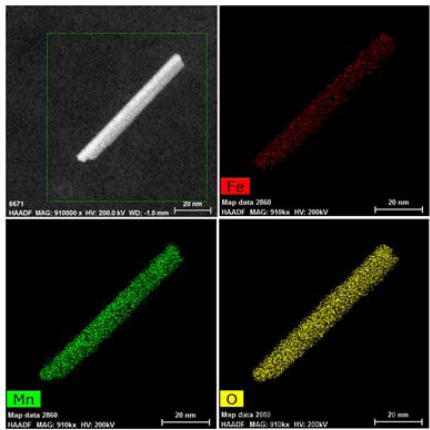

(f)
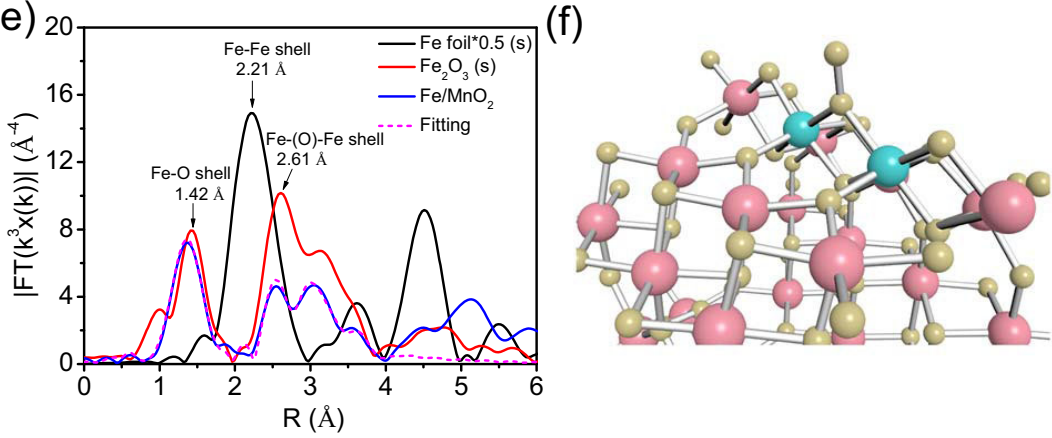

Fig. 1 Structure characterization of $\mathbf{F e} / \mathbf{M n O}_{\mathbf{2}} \cdot \mathbf{a}$ and $\mathbf{b} \mathrm{HAADF}-\mathrm{STEM}$ images of $\mathrm{Fe} / \mathrm{MnO}_{2}$ at different magnifications. $\mathbf{c}$ Element mapping images of Fe/ $\mathrm{MnO}_{2}$. d Normalized XANES spectra of Fe. e Fourier-transformed K-edge EXAFS spectra in R-space of Fe (without phase correction) and the fitting of Fe/ $\mathrm{MnO}_{2}$ structure in (f).

(a)

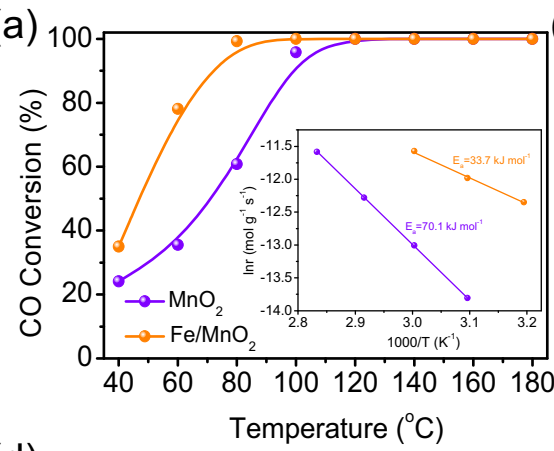

(d)

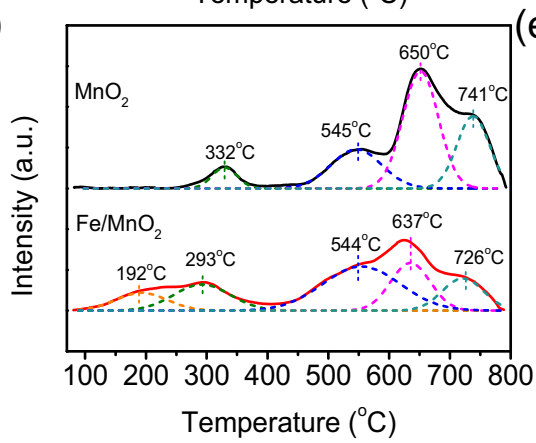

(b)

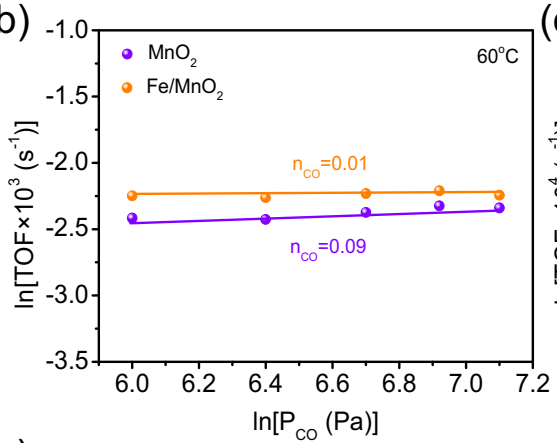

(e)

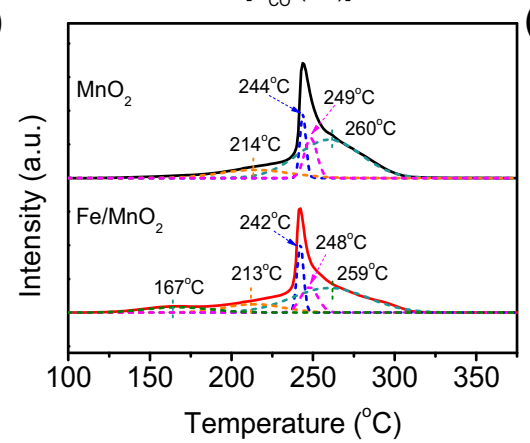

(c)

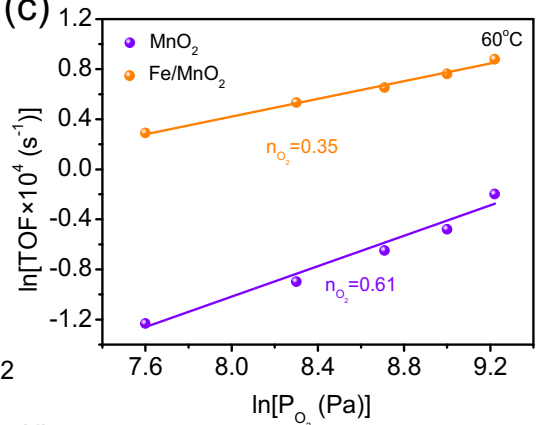

(f)

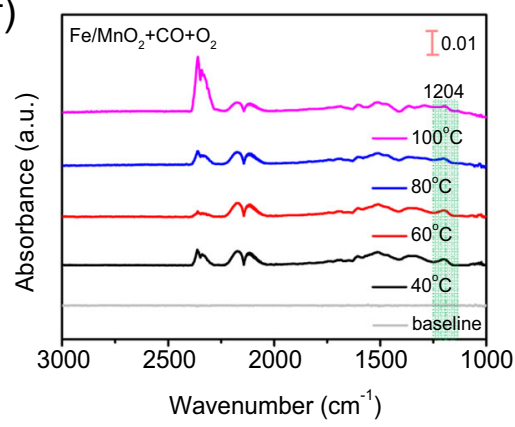

Fig. 2 Detection of active species. a Light-off curves of $\mathrm{CO}$ oxidation over $\mathrm{Fe} / \mathrm{MnO}_{2}$ and $\mathrm{MnO}_{2}$ (the inset shows associated Arrhenius plots). Effect of (b) $\mathrm{CO}$ and (c) $\mathrm{O}_{2}$ partial pressure on TOF of supported $\mathrm{Fe} / \mathrm{MnO}_{2}$ and $\mathrm{MnO}_{2}$ at $60^{\circ} \mathrm{C}$, respectively. $\mathbf{d ~} \mathrm{O}_{2}-\mathrm{TPD}$ profiles and e $\mathrm{H}_{2}-\mathrm{TPR}$ profiles of Fe/MnO $\mathrm{M}_{2}$ and $\mathrm{MnO}_{2}$. $\mathbf{f}$ In-situ DRIFTS of $\mathrm{CO}$ oxidation over $\mathrm{Fe} / \mathrm{MnO}_{2}$ in a continuous flow of $1 \% \mathrm{CO} / 4 \% \mathrm{O}_{2} / \mathrm{N}_{2}$ at different temperatures.

(Fig. 2d). The $\mathrm{O}_{2}$-TPD profile of $\mathrm{MnO}_{2}$ could be deconvoluted into four peaks of $<400,400-550,550-700^{\circ} \mathrm{C}$ and above $700^{\circ} \mathrm{C}$, corresponding to surface adsorbed oxygen $\left(\mathrm{O}_{\mathrm{ad}}\right)$, surface lattice oxygen ( $\left(\mathrm{S}-\mathrm{O}_{\text {latt }}\right.$ ) bound to $\mathrm{Mn}^{3+}$, $\mathrm{S}-\mathrm{O}_{\text {latt }}$ and bulk lattice oxygen $\left(\mathrm{B}-\mathrm{O}_{\text {latt }}\right)$ bound to $\mathrm{Mn}^{4+}$, respectively ${ }^{22}$. Besides these four peaks, an additional characteristic peak at $192{ }^{\circ} \mathrm{C}$ appeared in the spectrum of $\mathrm{Fe} / \mathrm{MnO}_{2}$, suggesting the emergence of new oxygen species formed on the surface. The formation of new oxygen species in $\mathrm{Fe} / \mathrm{MnO}_{2}$ was further confirmed by the new characteristic peak located at $167^{\circ} \mathrm{C}$ in $\mathrm{H}_{2}$-TPR (Fig. 2e) and the 

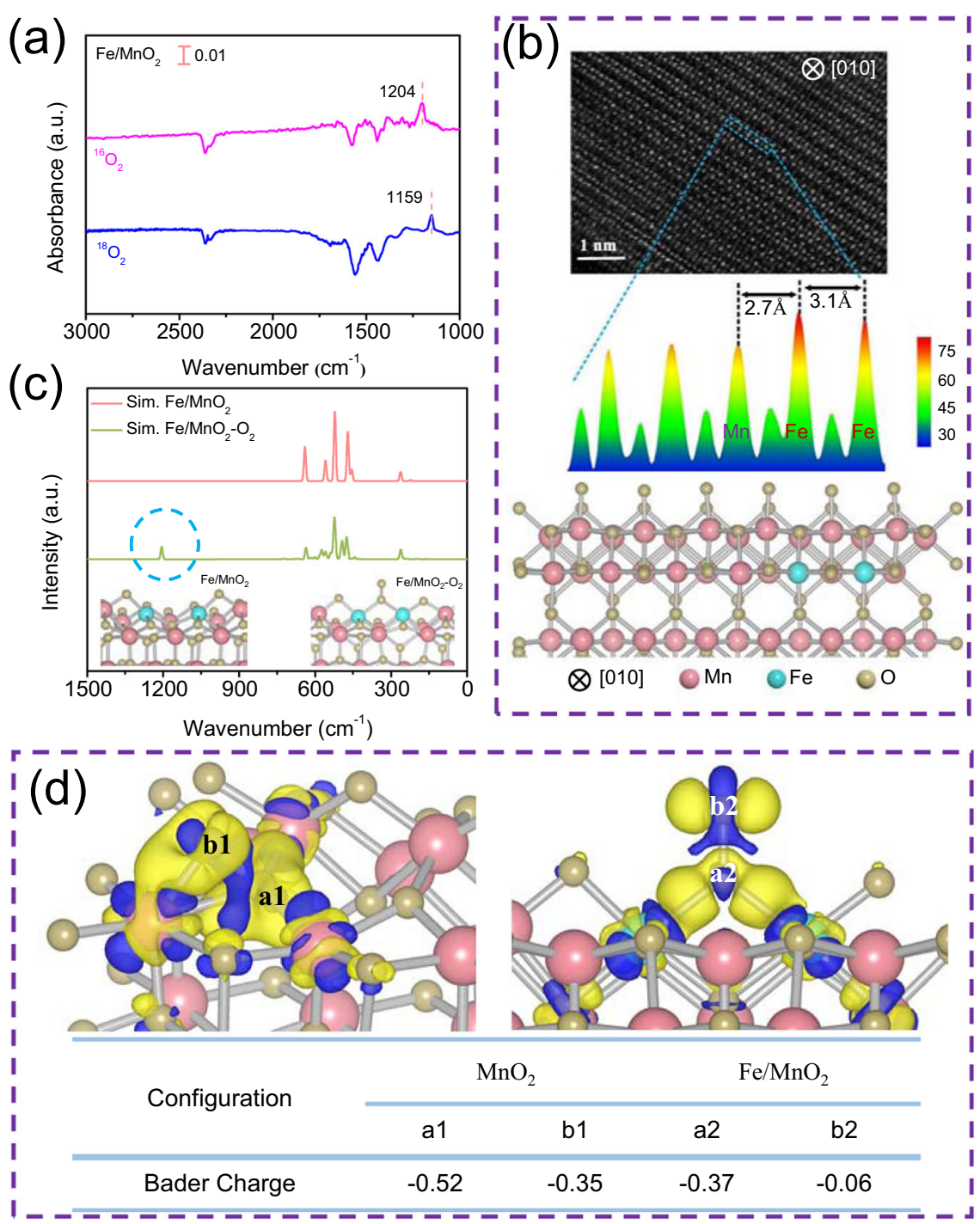

Fig. 3 Detection of active sites. a In-situ DRIFTS of ${ }^{18} \mathrm{O}_{2}$ isotope over $\mathrm{Fe} / \mathrm{MnO}_{2}$ in the out-line system. $\mathbf{b} \mathrm{STEM}$ image of Fe/ $\mathrm{MnO} 2$ (top), intensity surface plot from blue dashed rectangle (middle) and the corresponding structural model (bottom). c simulated infrared spectra of $\mathrm{Fe} / \mathrm{MnO}_{2}$ and Fe/ $\mathrm{MnO} \mathrm{O}_{2}$ with $\mathrm{O}_{2}$ adsorption. The bottom of the picture was the structure of the different species. $\mathbf{d}$ The difference charge density of $\mathrm{O}_{2}$ adsorbed on $\mathrm{MnO}_{2}$ (on the upper left) and $\mathrm{Fe} / \mathrm{MnO}_{2}$ (on the upper right). Different oxygen atoms from adsorbed oxygen species were labeled as $\mathbf{a}$ and $\mathbf{b}$, and corresponding Bader charge was recorded in the bottom of charge density map. The charge density of yellow and blue represents the concentrated and scarce electrostatic potential scale respectively.

increased adsorbed oxygen species on $\mathrm{Fe} / \mathrm{MnO}_{2}$ surface according to the result of O 1s XPS (Supplementary Fig. 11, Supplementary Table 1), respectively. These experimental results indicated that the excellent catalytic activity of $\mathrm{Fe} / \mathrm{MnO}_{2}$ might be attributed to the generation of new active oxygen species.

Subsequently, in-situ diffuse reflectance infrared Fourier transform spectroscopy (DRIFTS) was employed to confirm the generation of new oxygen species during $\mathrm{CO}$ oxidation over Fe/ $\mathrm{MnO}_{2}$. After only passing $\mathrm{CO}$ through the surface of the catalyst, gas phase CO peaks appeared at 2172 and $2113 \mathrm{~cm}^{-1}$ (Supplementary Fig. 12). The peaks at 1520 and $1365 \mathrm{~cm}^{-1}$ were ascribed to the symmetric and antisymmetric expansion vibration of carbonate, and others at 2361 and $2335 \mathrm{~cm}^{-1}$ were originated from the vibration of $\mathrm{CO}_{2}$ produced on the catalyst surface. Interestingly, a new characteristic peak arose at $1204 \mathrm{~cm}^{-1}$ in case of $\mathrm{CO}$ and $\mathrm{O}_{2}$ co-passing (Fig. $2 \mathrm{f}$ ). When ${ }^{16} \mathrm{O}_{2}$ was replaced by ${ }^{18} \mathrm{O}_{2}$, this characteristic peak shifted from $1204 \mathrm{~cm}^{-1}$ to the lower wavenumber of $1159 \mathrm{~cm}^{-1}$ due to the isotopic effect (Fig. 3a), indicating that this peak was closely related to the new active oxygen species generated via $\mathrm{O}_{2}$ activation on $\mathrm{Fe} / \mathrm{MnO}_{2}{ }^{23}$.

To determine the configuration of oxygen species, we compared the adsorption energy of different possible configurations of $\mathrm{O}_{2}$ adsorbed on $\mathrm{Fe} / \mathrm{MnO}_{2}$ (Supplementary Fig. 13a-e), and interestingly found that $\mathrm{Fe}(\mathrm{O}=\mathrm{O}) \mathrm{Fe}$ formed via bridging two adjacent $\mathrm{Fe}$ atoms with $\mathrm{O}_{2}$ in end-on mode possessed the highest adsorption energy, indicating that this new structure of $\mathrm{Fe}(\mathrm{O}=\mathrm{O}) \mathrm{Fe}$ was the preferentially adsorbed configuration of $\mathrm{O}_{2}$. The existence of adjacent $\mathrm{Fe}$ atoms was thus validated by the STEM image of the (010) exposed $\mathrm{Fe} / \mathrm{MnO}_{2}$ catalyst (the top of Fig. 3b). According to the STEM test on bare $\mathrm{MnO}_{2}$ (Supplementary Fig. 14), the intensity and the distance between the atoms $(2.9 \AA)$ are in accordance with the theoretical calculation model of $\mathrm{MnO}_{2}{ }^{24}$. As shown in the corresponding selection-area intensity surface plot (the middle of Fig. 3b), the different peak intensities corresponded to the atomic number, so the higher and lower peaks are attributed to $\mathrm{Fe}$ and $\mathrm{Mn}^{25}$, 
respectively. Therefore, the distance between two adjacent $\mathrm{Fe}$ atoms is $3.1 \AA$, larger than that $(2.7 \AA)$ between $\mathrm{Mn}$ and $\mathrm{Fe}$, consistent with the results of DFT calculation results (the bottom of Fig. 3b). Based on the analysis of element intensity in different positions of the STEM image, many two adjacent single-atom Fe sites were distributed on the surface of $\mathrm{Fe} / \mathrm{MnO}_{2}$ (Supplementary Fig. 15). Subsequently, we statistically analyzed the STEM spectra of 300 atoms in three regions on the surface of different $\mathrm{Fe} / \mathrm{MnO}_{2}$ catalysts (Supplementary Figs. 16, 17 and Supplementary Table 2), and found that $80.9 \%$ of $\mathrm{Fe}$ (the number of adjacent $\mathrm{Fe}$ atoms $\geq 2$ ) on the surface were distributed as adjacent $\mathrm{Fe}$ sites for $0.25 \% \mathrm{Fe} /$ $\mathrm{MnO}_{2}$, with a small number (19.1\%) as monatomic Fe site. Obviously, these adjacent $\mathrm{Fe}$ sites strongly contributed to the efficient activation of molecular oxygen. Meanwhile, the fitting result (dot line in Fig. 1e) of the model established by DFT simulation (Fig. 1f) well overlapped with the experimental measurement results within the range of $4 \AA$ from scattering atoms in the EXAFS spectrum of Fe. Furthermore, we simulated the infrared spectra of $\mathrm{Fe} / \mathrm{MnO}_{2}$ and $\mathrm{Fe} / \mathrm{MnO}_{2}$ with $\mathrm{O}_{2}$ adsorption by DFT calculation (Fig. 3c). In the simulated infrared spectrum of $\mathrm{Fe} / \mathrm{MnO}_{2}$ with $\mathrm{O}_{2}$ adsorption in end-on mode, a new characteristic peak appeared near $1200 \mathrm{~cm}^{-1}$, which was consistent with the experiment results. We also calculated the situation for two oxygen atoms of oxygen molecule attached to two Fe sites in side-on mode (Supplementary Fig. 13b). Two oxygen atoms got the same number of electrons, and the electron density was evenly distributed among the adsorbed oxygen molecules on the basis of the results of Bader charge and the differential charge density (Supplementary Fig. 18). Therefore, the dipole moment of oxygen molecules did not change during the vibration process in case of side-on mode, inconsistent with the results of the in-situ DRIFTS, thus further confirming the formation of $\mathrm{Fe}(\mathrm{O}=\mathrm{O}) \mathrm{Fe}$ species $^{26}$.

The role of $\mathrm{Fe}(\mathrm{O}=\mathrm{O}) \mathrm{Fe}$ on the $\mathrm{O}_{2}$ activation was further checked by in-situ DRIFTS. The peak strength of $\mathrm{Fe}(\mathrm{O}=\mathrm{O}) \mathrm{Fe}$ species at $1204 \mathrm{~cm}^{-1}$ increased along with passing $\mathrm{O}_{2}$ over $\mathrm{Fe} /$ $\mathrm{MnO}_{2}$ (Supplementary Fig. 19a). When $\mathrm{O}_{2}$ was changed to $\mathrm{CO}$, this peak became weakened and finally disappeared, with generating $\mathrm{CO}_{2}$ and carbonate species on the catalyst surface (Supplementary Fig. 19b). Therefore, we proposed that Fe atoms served as the active site for molecular oxygen activation, producing $\mathrm{Fe}(\mathrm{O}=\mathrm{O}) \mathrm{Fe}$ to oxidize $\mathrm{CO}$. In order to further confirm the mode of $\mathrm{Fe}(\mathrm{O}=\mathrm{O}) \mathrm{Fe}$ participation in the $\mathrm{CO}$ oxidation, $\mathrm{Cl}_{2}$ was introduced into the oxidation system ${ }^{27-29}$. For $\mathrm{Fe} / \mathrm{MnO}_{2}$ with pre-injecting $\mathrm{O}_{2}$ and $\mathrm{Cl}_{2}$ successively, the amount of $\mathrm{Fe}(\mathrm{O}=\mathrm{O}) \mathrm{Fe}$ and intermediate species did not change even after 30 min when $\mathrm{CO}$ was added to the reactor (Supplementary Figs. 20,21), indicating that $\mathrm{Cl}_{2}$ occupied $\mathrm{CO}$ adsorption sites and prevented $\mathrm{Fe}(\mathrm{O}=\mathrm{O}) \mathrm{Fe}$ from participating in the reaction. Therefore, $\mathrm{Fe}(\mathrm{O}=\mathrm{O}) \mathrm{Fe}$ species might react with adsorbed $\mathrm{CO}$ through Langmuir-Hinshelwood (L-H) mechanism, different from surface oxygen vacancies $\left(\mathrm{V}_{\mathrm{O}}\right)$ of $\mathrm{MnO}_{2}$ via the Mars-van Krevelen $(\mathrm{MvK})$ reaction mechanism ${ }^{30}$.

Oxygen activation mechanism. To better understand the $\mathrm{O}_{2}$ activation and $\mathrm{CO}$ oxidation performance of $\mathrm{Fe}(\mathrm{O}=\mathrm{O}) \mathrm{Fe}$, we compared the $\mathrm{O}_{2}$ adsorption in $\mathrm{Fe} / \mathrm{MnO}_{2}$ with two adjacent single-atom $\mathrm{Fe}$ sites and $\mathrm{MnO}_{2}$ with $\mathrm{V}_{\mathrm{O}}$. The adsorption energy $(-2.00 \mathrm{eV})$ of bridging two adjacent $\mathrm{Fe}$ atoms with $\mathrm{O}_{2}$ was relatively higher than that $(-0.83 \mathrm{eV})$ of $\mathrm{O}_{2}$ adsorption over $\mathrm{V}_{\mathrm{O}}$ (Supplementary Fig. 13). Subsequently, the bonding situation of $\mathrm{O}_{2}$ adsorbed in two different sites was further compared by differential charge density maps. As shown in Fig. 3d, the oxygen atoms al and b1 (from the adsorbed oxygen molecules on the $\mathrm{V}_{\mathrm{O}}$ ) are bound with the unsaturated $\mathrm{Mn}$ sites in $\mathrm{MnO}_{2}$. The strong electron scale is distributed among the valence bonds, indicating the formation of a firm chemical bond between oxygen atoms and Mn sites. The feedback $\pi$ electrons of Mn $d$ orbital are transferred to the vacant orbital of oxygen, resulting in the higher charge density of oxygen atoms. The correlation results are proved by Bader charge (bottom of Fig. 3d). For $\mathrm{Fe} / \mathrm{MnO}_{2}$, oxygen atom a 2 gets the electrons from two adjacent double $\mathrm{Fe}$ atoms with the Bader charge of -0.37 , while oxygen atom b2 is weakly bonded with a2 becasue of scarce electrostatic potential scale located at $\mathrm{O}-\mathrm{O}$ bond. We also calculated crystal orbital Hamilton populations (COHP) of $\mathrm{O}_{2}$ adsorbed on $\mathrm{MnO}_{2}$ and $\mathrm{Fe} /$ $\mathrm{MnO}_{2}$ (Fig. $4 \mathrm{a}-\mathrm{c}$ ). Integral crystal orbital Hamilton populations (ICOHP) results (Fig. 4d) showed that the intensity of $\mathrm{O}-\mathrm{O}$ bond from $\mathrm{O}_{2}$ adsorbed on the double $\mathrm{Fe}$ sites was weaker than that on $\mathrm{MnO}_{2}\left(-\mathrm{ICOHP}=2.73 / 2.44\right.$ vs. $-\mathrm{ICOHP}=3.50 / 3.18$ for $\left.\mathrm{MnO}_{2}\right)$. So, b2 with the end-on mode of $\mathrm{O}_{2}$ on adjacent Fe sites might easily escape to participate in the subsequent reaction, accounting for the facile molecular oxygen activation of two adjacent singleatom Fe sites with the lower activity barrier.

Furthermore, we compared the activation behavior of oxygen at $\mathrm{Fe}-\mathrm{Fe}$ or $\mathrm{Fe}-\mathrm{Mn}$ bimetallic sites, and found that the double $\mathrm{Fe}$ sites mainly contributed to the molecular oxygen activation of $\mathrm{Fe} /$ $\mathrm{MnO}_{2}$ (Supplementary Fig. 22). Importantly, the oxalatechelating coordinated hydrothermal method enables the uniform dispersion of monatomic Fe on the surface of the catalyst, constructing abundant active sites composed of adjacent Fe atoms (Supplementary Figs. 23-26). The results are also verified by etching XPS spectra (Supplementary Fig. 27).

DFT calculation was thus carried out to calrify the contribution of two adjacent single-atom $\mathrm{Fe}$ sites to the $\mathrm{CO}$ oxidation on $\mathrm{Fe} /$ $\mathrm{MnO}_{2}$ (Fig. 5). First, $\mathrm{CO}$ was adsorbed on the $\mathrm{Mn}$ site ${ }^{26}$, which was connected to $\mathrm{Fe}(\mathrm{O}=\mathrm{O}) \mathrm{Fe}$ species with lattice oxygen. Being of the electronegativity, oxygen atom (b2) in $\mathrm{Fe}(\mathrm{O}=\mathrm{O}) \mathrm{Fe}$ was inclined to bond with carbon atom in $\mathrm{CO}$ (Supplementary Fig. 28). After overcoming the activation barrier of $0.17 \mathrm{eV}, \mathrm{CO}_{2}$ was formed and desorbed, leaving behind another $\mathrm{O}$ atom (a2). Subsequently, the lattice oxygen connected to the $\mathrm{Mn}$ site reacted with the second adsorbed $\mathrm{CO}$ to produce another $\mathrm{CO}_{2}$ molecule by overcoming the activation energy of $0.51 \mathrm{eV}$. Then the remained oxygen atom (a2) between two adjacent Fe sites moved to refill the position of $\mathrm{V}_{\mathrm{O}}$. Finally, the surface structure of $\mathrm{Fe} /$ $\mathrm{MnO}_{2}$ returned to its original state through the re-adsorption of $\mathrm{O}_{2}$, realizing a full catalytic cycle of $\mathrm{CO}$ oxidation. Furthermore, we also calculated the energy of $\mathrm{CO}$ reacting with $\mathrm{O}_{2}$ on different sites. The calculation results of the transition state revealed that the energy $(0.19 \mathrm{eV})$ for $\mathrm{CO}$ reacting with $\mathrm{O}_{2}$ adsorbed on the adjacent $\mathrm{Fe}$ sites was lower than that $(0.37 \mathrm{eV})$ of $\mathrm{O}_{2}$ adsorbed on the $\mathrm{V}_{\mathrm{O}}$ referring to Supplementary Fig. 29. Therefore, the MvK mechanism on bare $\mathrm{MnO}_{2}$ could be inhibited by the high energy demand. As expected, the total $\mathrm{CO}$ oxidation reaction barrier $(0.51 \mathrm{eV})$ of $\mathrm{Fe} / \mathrm{MnO}_{2}$ was much lower than that $(0.86 \mathrm{eV})$ of $\mathrm{MnO}_{2}$ (Supplementary Fig. 30), where $\mathrm{V}_{\mathrm{O}}$ governed both molecular oxygen activation and $\mathrm{CO}$ oxidation $^{31-34}$. Two adjacent single-atom $\mathrm{Fe}$ sites on $\mathrm{MnO}_{2}$ possessed significantly higher activity by forming $\mathrm{Fe}(\mathrm{O}=\mathrm{O}) \mathrm{Fe}$ species than conventional $\mathrm{V}_{\mathrm{O}}$ to activate oxygen molecules.

\section{Discussion}

In general, we constructed adjacent single-atom Fe-active sites to activate oxygen molecular by forming intermediate species $\mathrm{Fe}(\mathrm{O}=\mathrm{O}) \mathrm{Fe}$ over $\mathrm{Fe} / \mathrm{MnO}_{2}$. The experimental and theoretical results revealed that $\mathrm{Fe} / \mathrm{MnO}_{2}$ exhibited lower reaction orders and lower activation barrier for oxygen activation than pure $\mathrm{MnO}_{2}$ with oxygen vacancy as the activation sites. Charge 

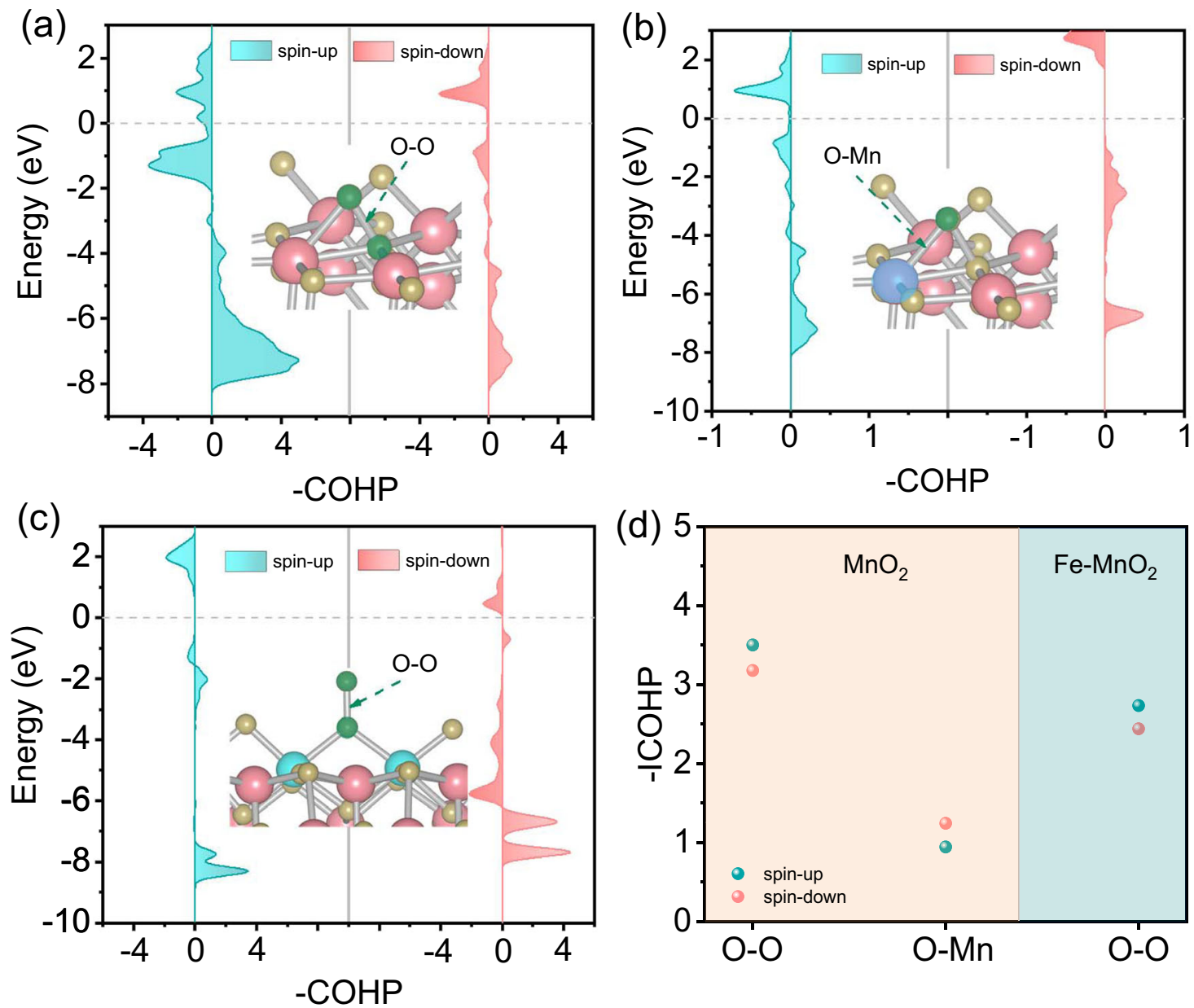

Fig. 4 Analysis of bonding strength. $\mathrm{COHP}$ of $\mathrm{MnO}_{2}(\mathbf{a}, \mathbf{b})$ and $\mathrm{Fe} / \mathrm{MnO}_{2}(\mathbf{c})$ at different positions. $\mathbf{d}$ The corresponding ICOHP in a-c. The insets in a-c show the corresponding structure.

localization and weak bond strength made pendant oxygen atoms more easily escape to participate in the subsequent oxidation reaction. This work offers dimer active sites for the dioxygen activation and opens up a path to promote oxidation reactions. More importantly, we believe that two adjacent single-atom active sites might be also more diverse and efficient for the activation of inert small molecules such as $\mathrm{N}_{2}, \mathrm{CO}_{2}, \mathrm{CH}_{4}$, etc.

\section{Methods}

All the reagents used in the synthesis process are analytical-grade and do not require further purification before use.

Synthesis of $\mathbf{F e} / \mathrm{MnO}_{2} . \mathrm{Fe} / \mathrm{MnO}_{2}$ catalysts were prepared by conventional hydrothermal methods, a modified method previously reported elsewhere ${ }^{35}$. During the synthesis process, $1.58 \mathrm{~g}$ potassium permanganate $\left(\mathrm{KMnO}_{4}\right)$ solid was dissolved in $30 \mathrm{~mL}$ deionized water, and then $20 \mathrm{~mL}$ of $35.5 \mathrm{~g} \mathrm{~L}^{-1}$ ammonium oxalate $\left(\left(\mathrm{NH}_{4}\right)_{2} \mathrm{C}_{2} \mathrm{O}_{4} \cdot \mathrm{H}_{2} \mathrm{O}\right)$ solution was added to the potassium permanganate solution drop by drop. After $0.5 \mathrm{~h}$ of stirring, the ferric nitrate $\left(\mathrm{Fe}\left(\mathrm{NO}_{3}\right)_{3} \cdot 9 \mathrm{H}_{2} \mathrm{O}\right)$ solution was transferred to the above mixture solution and stirred again at room temperature for another $1 \mathrm{~h}$. The mixture was transferred to Teflon bottle into a stainless-steel autoclave reacted for $24 \mathrm{~h}$ at $180^{\circ} \mathrm{C}$. After cooling to room temperature, the powder products were washed and filtered repeatedly, and dried at $105^{\circ} \mathrm{C}$ for $12 \mathrm{~h}$. The resulting gray-black powder was placed in a corundum crucible and calcined for $2 \mathrm{~h}$ at $350^{\circ} \mathrm{C}$ under ambient air. $\mathrm{Fe} / \mathrm{MnO}_{2}$ catalysts with different contents were obtained by changing the mass of iron nitrate. The obtained catalyst was labeled as $\mathrm{N} \% \mathrm{Fe} / \mathrm{MnO}_{2}$, and $\mathrm{N}$ represented the ratio of $\mathrm{Fe}$ to $\mathrm{MnO}_{2}$. The preparation of pure $\mathrm{MnO}_{2}$ remained unchanged except that no iron nitrate was added to the precursor solution.
Synthesis of $\mathbf{F e} / \mathbf{M n O}_{\mathbf{2}}-\mathbf{1 0 0}^{\circ} \mathrm{C}$. The preparation process is the same as that of $\mathrm{Fe} / \mathrm{MnO}_{2}$, except that the hydrothermal reaction temperature is $100^{\circ} \mathrm{C}$ instead of $180^{\circ} \mathrm{C}$ and is not calcined at $350^{\circ} \mathrm{C}$.

Synthesis of $\mathrm{Fe}_{2}\left(\mathrm{C}_{2} \mathrm{O}_{4}\right)_{3}-\mathbf{1 0 0}^{\circ} \mathrm{C}$. The ferric nitrate particle was dissolved in $30 \mathrm{~mL}$ deionized water and stirred for $30 \mathrm{~min}$. The solution was added to $40 \mathrm{~mL}$ ammonium oxalate solution $\left(35.5 \mathrm{~g} \mathrm{~L}^{-1}\right)$ one by one. After stirring for $1 \mathrm{~h}$, the mixture was transferred to the oven and reacted at $100^{\circ} \mathrm{C}$ for $24 \mathrm{~h}$. After cooling to room temperature, the powder products were washed and filtered repeatedly and dried at $105^{\circ} \mathrm{C}$ for $12 \mathrm{~h}$.

Catalysts characterization. The as-prepared catalyst of X-ray diffraction (XRD) patterns is obtained through the Rigaku D/MAXRB diffractometer equipped with monochromatized $\mathrm{Cu} \mathrm{K}$ alpha radiation, and scanning range of 2 theta angle changes from $20^{\circ}$ to $80^{\circ}$. Aberration-corrected HAADF-STEM measurements are completed by using Titan transmission electron microscope operated at $300 \mathrm{keV}$. Different elements of energy-dispersive spectroscopy (EDX) were obtained on the same equipment. The actual element content of the catalyst was analyzed by an inductively coupled plasma optical emission spectrometer (ICP-OES) based on dissolved samples in aqua regia. The valences of different elements on the surface of the catalyst were analyzed by XPS (Thermo Scientific Escalab 250 Xi analyzer). The binding energy of each element was corrected based on the C1s spectrum at $284.8 \mathrm{eV}$. The XAFS test was conducted at the Beijing synchrotron radiation center. The sample was ground evenly and smeared into Scotch tapes. K-edge absorption of Fe and Mn elements was tested in fluorescent mode at room temperature. The samples were tested several times and the average results were further analyzed. Data is processed through ${ }^{36}$. The EXAFS spectrum of Fe was fitted in the R space by a theoretical model based on VASP optimization results according to the shorter absorption layer of $\mathrm{Fe}$ (including first $\mathrm{Fe}-\mathrm{O}, \mathrm{Fe}-(\mathrm{O})-\mathrm{Mn}$, and $\mathrm{Fe}-(\mathrm{O})-\mathrm{Fe}$ shell). The corresponding fitting parameters are listed in Supplementary Table 3. The oxidation and reduction properties of samples can be compared through the hydrogen temperature-programmed reduction $\left(\mathrm{H}_{2}-\mathrm{TPR}\right)$ and oxygen temperatureprogrammed desorption $\left(\mathrm{O}_{2}-\mathrm{TPD}\right)$ experiments monitored by the Chemisorb tp- 


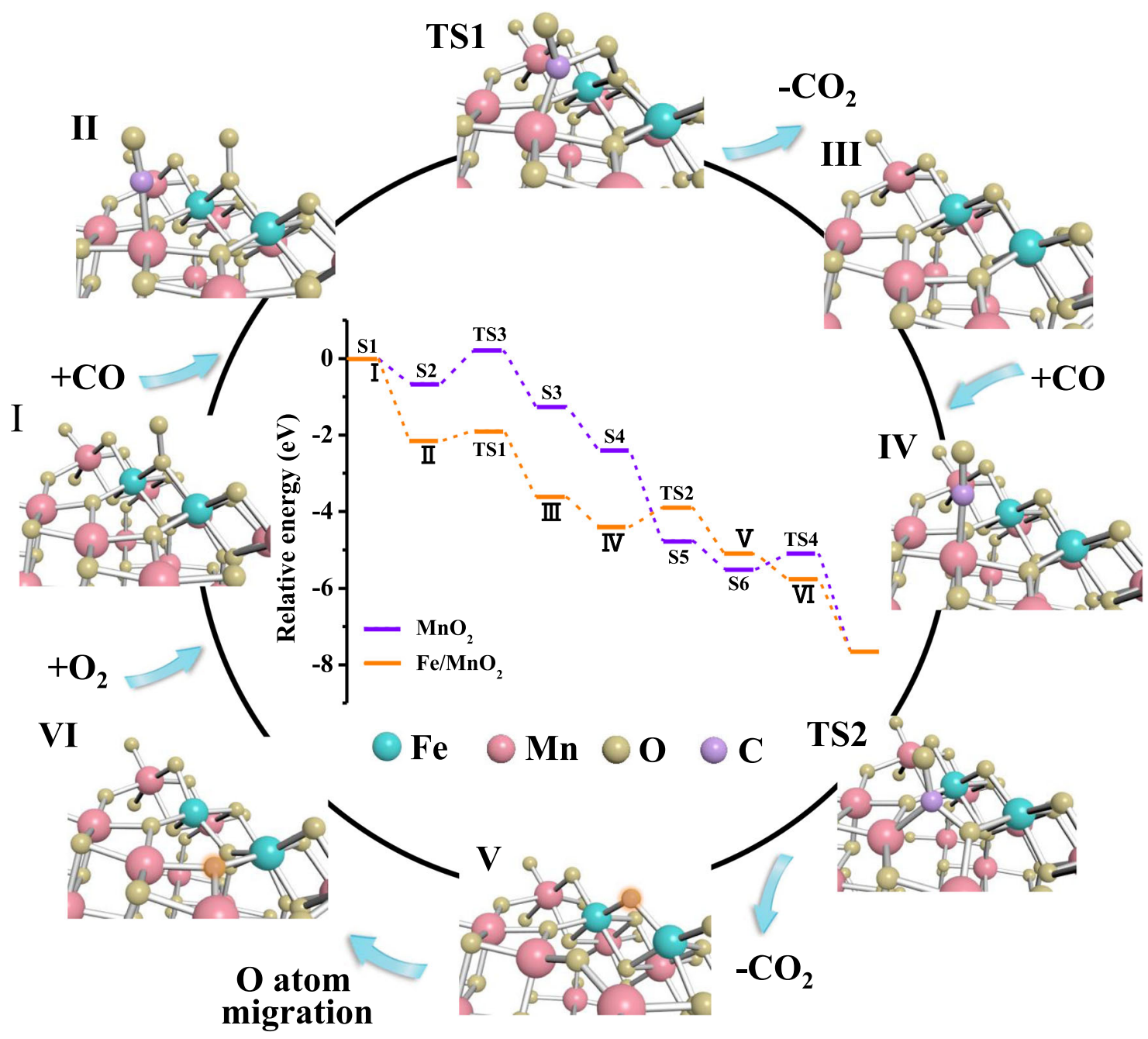

Fig. 5 Mechanistic investigations. Proposed reaction mechanism for $\mathrm{CO}$ oxidation on $\mathrm{Fe} / \mathrm{MnO}_{2}$ surface. The inset shows the calculated energy profiles in $\mathrm{eV}$. The structures of intermediates and transition states are shown in the reaction cycle. The energy profile of the reaction cycle for $\mathrm{Fe} / \mathrm{MnO}_{2}$ is shown by the orange line in the inset. The purple line shows the energy profile for $\mathrm{MnO}_{2}$ (reaction cycle is shown in Supplementary Fig. 30).

5080 with a thermal conductivity detector (TCD). Before the test, $100 \mathrm{mg}$ catalyst was pretreated at $105^{\circ} \mathrm{C}$ in an argon atmosphere for $30 \mathrm{~min}$. After natural cooling to room temperature, measurement was started. For $\mathrm{O}_{2}$-TPD, the samples were exposed to an atmosphere of $20 \% \mathrm{O}_{2} / \mathrm{Ar}\left(50 \mathrm{~mL} \mathrm{~min}^{-1}\right)$ for $1 \mathrm{~h}$ and then heated to $800{ }^{\circ} \mathrm{C}$ under $\mathrm{N}_{2}$ atmosphere with $5^{\circ} \mathrm{C} \mathrm{min}^{-1}$. For $\mathrm{H}_{2}$-TPR, $5 \% \mathrm{H}_{2} / \mathrm{Ar}$ was continuously fed into the reactor containing the samples, and the temperature rose to $800{ }^{\circ} \mathrm{C}$ at a rate of $5^{\circ} \mathrm{C} \mathrm{min}^{-1}$. The whole flow is recorded by TCD. During the catalytic reaction of $\mathrm{CO}$ oxidation, the in-situ reaction process of the catalyst surface was recorded in the DRIFTS (Nicolet iS50, Thermo). For the off-line system, the catalyst was treated at $300^{\circ} \mathrm{C}$ for $30 \mathrm{~min}$ before testing to remove the oxidized species adsorbed on the catalyst surface. Then cooled naturally to room temperature, background noise was removed and the baseline was recorded. When the temperature was raised to the preset value, a certain volume of $\mathrm{CO}$ or $\mathrm{O}_{2}$ was injected into the reaction device, and the spectrogram was collected. When the spectrogram no changed over time, it was the test result at this temperature. On the other hand, for the on-line system, the catalyst was pretreated at $300^{\circ} \mathrm{C}$ for $30 \mathrm{~min}$ in the atmosphere of $\mathrm{N}_{2}$, cooled to $40^{\circ} \mathrm{C}$, and deducted the background followed by collecting baseline. Accompanied by the temperature maintained at $40{ }^{\circ} \mathrm{C}, 1 \% \mathrm{CO} /$ $\mathrm{N}_{2}$ and $1 \% \mathrm{CO} / 4 \% \mathrm{O}_{2} / \mathrm{N}_{2}$ were continued to flow through the catalyst and the total flow rate was $50 \mathrm{~mL} \mathrm{~min}{ }^{-1}$, respectively. The in-situ spectrogram was recorded with time. For in-situ DRIFTS reaction involving $\mathrm{Cl}_{2}$, after high-temperature pretreatment, $20 \mathrm{~mL}$ of $\mathrm{Cl}_{2}$ was injected into a reactor containing $\mathrm{MnO}_{2}$ at $40{ }^{\circ} \mathrm{C}$ After the spectrum was stabilized, it could be observed that the peak of adsorbed species on the catalyst surface decreased significantly, and the characteristic peak of $\mathrm{CO}_{2}$ was generated at the same time. Subsequently, $20 \mathrm{~mL} \mathrm{CO}$ was injected into the closed system, and an obvious adsorption peak of $\mathrm{CO}$ appeared in the spectrum. The in-situ spectrogram was recorded for $30 \mathrm{~min}$. As for $\mathrm{Fe} / \mathrm{MnO}_{2} .20 \mathrm{~mL} \mathrm{O}$ was injected into the vacuum reaction chamber at $100^{\circ} \mathrm{C}$, and the DRIFTS spectra were recorded immediately. After the temperature was lowered to $40^{\circ} \mathrm{C}, 20 \mathrm{~mL} \mathrm{Cl}_{2}$ was injected into the reactor. The absorption peak of $\mathrm{Cl}_{2}$ appeared in the spectrum.
Then, $20 \mathrm{~mL}$ of $\mathrm{CO}$ has added to the system again, and a significant vibration peak of $\mathrm{CO}$ appeared. When the spectrogram is stable, the corresponding results are recorded, respectively.

Catalytic performance evaluation. All catalyst was tested in a continuous flow reactor. The newly prepared catalyst of $100 \mathrm{mg}$ was loaded into a quartz tube with an internal diameter of $1 \mathrm{~mm}$, and $1 \% \mathrm{CO}, 4 \% \mathrm{O}_{2}$, and $95 \% \mathrm{~N}_{2}$ were fed into the reactor at the hourly space velocity (GHSV) of $30,000 \mathrm{~mL} \mathrm{~g}^{-1} \mathrm{~h}^{-1}$. The residual gas content composition was analyzed by online gas chromatography with a flame detector (FID). The temperature interval with $20^{\circ} \mathrm{C}$ was used to study the relationship between different reaction temperatures and $\mathrm{CO}$ conversion performance. Test, at the same temperature many times, was recorded as the corresponding light-off conversion rates after the conversion effect remained stable. The conversion effect of $\mathrm{CO}$ is calculated using Eq. (1):

$$
\eta(\%)=\frac{C_{\text {in }}-C_{\text {out }}}{C_{\text {in }}} \times 100 \%
$$

where $C_{\text {in }}$ and $C_{\text {out }}$ represent the $\mathrm{CO}$ concentration in the inflow and outflow reaction system, respectively, determined by gas chromatography.

At a constant temperature, the relationship between the exchange frequency (TOF) and the partial pressure of $\mathrm{CO}$ was tested. By keeping the partial pressure of $\mathrm{O}_{2}$ unchanged at $4 \mathrm{kPa}$, the partial pressure of $\mathrm{CO}$ changed from 4 to $5.6 \mathrm{kPa}$. On the contrary, in order to explore the effect of partial pressure of $\mathrm{O}_{2}$ on the reaction rate, the partial pressure of $\mathrm{CO}$ was kept unchanged at $4 \mathrm{kPa}$, and the partial pressure of $\mathrm{O}_{2}$ was adjusted from 4 to $12 \mathrm{kPa}$.

The specific reaction rate $\left(R_{\mathrm{CO}}\right)$ was calculated by Eq. (2):

$$
R_{\mathrm{CO}}=\frac{v_{\text {gas }} \times \eta}{m_{\text {cat }}}
$$


where $v_{\text {gas }}$ represents the molar gas flow rate $\left(\mathrm{mol} \mathrm{h}^{-1}\right)$, and $m_{\text {cat }}$ is the mass of the catalyst (g).

Turnover frequency (TOF) was calculated by Eq. (3):

$$
\mathrm{TOF}=\frac{R_{\text {gas }} \times M}{\delta_{\text {cat }}}
$$

where $M$ represents the molar weight of $\mathrm{Mn}$ or $\mathrm{Fe}$, and $\delta_{\text {cat }}$ represents the percentage of active sites from the catalyst. For $\mathrm{MnO}_{2}$, the number of Mn sites (for $\mathrm{Fe} / \mathrm{MnO}_{2}$, the number of $\mathrm{Mn}$ and Fe sites) is calculated based on the ICP-OES results.

Arrhenius plots at different temperature ranges were tested by varying the catalyst mass (5-50 mg, diluted with quartz sand of $200 \mathrm{mg}$ ), CO concentration $(2-2.4 \%)$, and carrier gas flow rates to ensure that $\mathrm{CO}$ conversion remained below $20 \%$, thus eliminating the effects of heat and mass transfer on kinetic testing. The setting of relevant specific reaction conditions was listed in Supplementary Table 4.

The apparent activation energy $\left(E_{\mathrm{a}}\right)$ is calculated as follows:

$$
k=A e^{-E_{\mathrm{a}} / R T}
$$

where $k$ is the rate constant, $A$ is the former factor, and $T$ is the temperature (K). $E_{a}$ is obtained by fitting the value of $\ln (r)$ at different temperatures.

Coverage of $\mathrm{Fe}$ atoms from $\mathrm{Fe} / \mathrm{MnO}_{2}$ :

$$
\begin{gathered}
m_{\mathrm{Fe}}=\frac{n_{\mathrm{Fe}} \times M_{\mathrm{Fe}}}{N_{\mathrm{A}}} \\
m_{\mathrm{Mn}}=\frac{n_{\mathrm{Mn}} \times M_{\mathrm{Mn}}}{N_{\mathrm{A}}} \\
m_{\mathrm{O}}=\frac{2 \times\left(n_{\mathrm{Mn}}+n_{\mathrm{Fe}}\right) \times M_{\mathrm{O}}}{N_{\mathrm{A}}} \\
N=\frac{H}{h} \\
W_{\mathrm{Fe}}=\frac{2 \times m_{\mathrm{Fe}}}{2 \times\left(m_{\mathrm{Fe}}+m_{\mathrm{Mn}}+m_{\mathrm{O}}\right)+300 \times m_{\mathrm{MnO}_{2}} \times N}
\end{gathered}
$$

where $m$ represents the mass of different element; $N$ is the number of atoms; $M$ is the relative atomic mass; $N_{\mathrm{A}}$ is the Avogadro constant; $H$ is the thickness of catalyst, which is counted by TEM test results. $h$ represents the height of singlelayer $\mathrm{MnO}_{2}$, which comes from the structural optimization model; $N$ is the number of layers; $W_{\mathrm{Fe}}$ is the mass fraction of Fe.

Specific activity was calculated by Eq. (10):

$$
R_{\mathrm{T} 50}=\frac{v_{\mathrm{CO}} \times M_{\mathrm{Fe}}}{m_{\mathrm{Fe}}}
$$

where $v_{\mathrm{CO}}$ represents the molar gas flow rate of $\mathrm{CO}\left(\mathrm{molh}^{-1}\right) ; M_{\mathrm{Fe}}$ is the relative atomic mass of Fe; $m_{\mathrm{Fe}}$ is the mass of Fe on the basis of ICP results and statistical results from $0.25 \% \mathrm{Fe} / \mathrm{MnO}_{2}$ STEM image.

\section{First-principles density functional theory (DFT) calculations. All surface} structures were simulated by the Vienna ab-initio simulation package (VASP), using GGA-PBE as the exchange-correlation functional, while the projector augmented wave (PAW) was utilized to handle the interaction of valence electrons with core and inner electrons $\mathrm{s}^{37-39}$. The plane-wave basis restriction with $520 \mathrm{eV}$ cutoff energy and the Hubbard $U$ for Mn $3 d$ at $3.9 \mathrm{eV}$ and Fe $3 d$ at $3.0 \mathrm{eV}$ are set for models ${ }^{40}$. Spin-polarization calculations were carried out for all systems. The convergence criteria for energy and force applied to all atoms are set at $10^{-5} \mathrm{eV}$ and $0.02 \mathrm{eV} \AA^{-1}$, respectively. The value of $k$ in the Brillouin zone is $3^{*} 3^{*} 1$. Meanwhile, in order to avoid the interaction between layers caused by periodic boundary conditions, the thickness of the vacuum layer of the surface structure is set to $20 \AA$ A. According to the experimental results (STEM), the surface (010) of the $2 * 2$ supercell $\mathrm{MnO}_{2}$ or $\mathrm{Fe} / \mathrm{MnO}_{2}$ was used as the exposure of the catalyst to stimulate the reaction process. The transition state of the catalytic reaction was determined using the climbing image nudged elastic band (Cl-NEB) method ${ }^{41,42}$. Zero-point energy correction was obtained from vibrational frequencies by applying normal-mode analysis through DFT calculations ${ }^{43}$. We fixed the catalyst substrate and only allowed the adsorbing molecule to vibrate.

The adsorption energy was defined by

$$
E_{\text {ads }}=E_{(\text {ads }+ \text { sur })}-E_{(\mathrm{ads})}-E_{(\text {sur })}
$$

where $E_{\text {(ads+sur) }}$ is the total energy of a surface interacting with adsorbate, and $E_{\text {(ads) }}$ and $E_{(\text {sur }}$ are the energies of the isolated adsorbate and clean surface, respectively. The energy is corrected by zero-point energy.

\section{Data availability}

All data generated in this study are provided in the Article and Supplementary Information. The other data that support the findings of this study are available from the corresponding author upon reasonable request.
Received: 10 March 2021; Accepted: 10 August 2021; Published online: 14 September 2021

\section{References}

1. Montemore, M. M., van Spronsen, M. A., Madix, R. J. \& Friend, C. M. $\mathrm{O}_{2}$ activation by metal surfaces: implications for bonding and reactivity on heterogeneous catalysts. Chem. Rev. 118, 2816-2862 (2018).

2. Mukherjee, D., Ellern, A. \& Sadow, A. D. Remarkably robust monomeric alkylperoxyzinc compounds from tris(oxazolinyl)boratozinc alkyls and $\mathrm{O}_{2}$. J. Am. Chem. Soc. 134, 13018-13026 (2012).

3. $\mathrm{Ma}, \mathrm{Y}$. et al. Investigation into the enhanced catalytic oxidation of o-xylene over MOF-derived $\mathrm{Co}_{3} \mathrm{O}_{4}$ with different shapes: The role of surface twofoldcoordinate lattice oxygen $\left(\mathrm{O}_{2 \mathrm{f}}\right)$. ACS Catal. 11, 6614-6625 (2021).

4. Li, H. et al. Analysis of the limitations in the oxygen reduction activity of transition metal oxide surfaces. Nat. Catal. 4, 463-468 (2021).

5. Liu, J.-X., Su, Y., Filot, I. A. W. \& Hensen, E. J. M. A linear scaling relation for CO oxidation on $\mathrm{CeO}_{2}$-supported Pd. J. Am. Chem. Soc. 140, 13624 (2018).

6. Yang, J. et al. Oxygen vacancy promoted $\mathrm{O}_{2}$ activation over perovskite oxide for low-temperature CO oxidation. ACS Catal. 9, 9751-9763 (2019).

7. Puigdollers, A. R. \& Pacchioni, G. CO oxidation on Au nanoparticles supported on $\mathrm{ZrO}_{2}$ : role of metal/oxide interface and oxide reducibility. ChemCatChem 9, 1119-1127 (2017).

8. Wang, J., Zhang, G. \& Zhang, P. Layered birnessite-type $\mathrm{MnO}_{2}$ with surface pits for enhanced catalytic formaldehyde oxidation activity. J. Mater. Chem. A 5, 5719-5725 (2017).

9. Wang, B., Cao, Z., Rovira, C., Song, J. \& Shaik, S. Fenton-derived OH radicals enable the MPnS enzyme to convert 2-hydroxyethylphosphonate to methylphosphonate: insights from ab initio QM/MM MD simulations. J. Am. Chem. Soc. 141, 9284-9291 (2019).

10. Qiao, B. et al. Single-atom catalysis of $\mathrm{CO}$ oxidation using $\mathrm{Pt}_{1} / \mathrm{FeO}_{\mathrm{x}}$. Nat. Chem. 3, 634-641 (2011).

11. Zhou, $\mathrm{X}$. et al. Unraveling charge state of supported Au single-atoms during CO oxidation. J. Am. Chem. Soc. 140, 554-557 (2018).

12. Chen, Y. et al. Sodium rivals silver as single-atom active centers for catalyzing abatement of formaldehyde. Environ. Sci. Technol. 51, 7084-7090 (2017).

13. Pan, X., Yang, M.-Q., Fu, X., Zhang, N. \& Xu, Y.-J. Defective $\mathrm{TiO}_{2}$ with oxygen vacancies: synthesis, properties and photocatalytic applications. Nanoscale 5, 3601-3614 (2013).

14. Luo, D. et al. Three-dimensional nitrogen-doped porous carbon anchored $\mathrm{CeO}_{2}$ quantum dots as an efficient catalyst for formaldehyde oxidation. $J$. Mater. Chem. A 6, 7897-7902 (2018).

15. Smith, R. D. L. et al. Spectroscopic identification of active sites for the oxygen evolution reaction on iron-cobalt oxides. Nat. Commun. 8, 2022 (2017).

16. Nie, $\mathrm{L}$. et al. Activation of surface lattice oxygen in single-atom $\mathrm{Pt} / \mathrm{CeO}_{2}$ for low-temperature CO oxidation. Science 358, 1419-1423 (2017).

17. Davó-Quiñonero, A. et al. Insights into the oxygen vacancy filling mechanism in $\mathrm{CuO} / \mathrm{CeO}_{2}$ catalysts: a key step toward high selectivity in preferential $\mathrm{CO}$ oxidation. ACS Catal. 10, 6532-6545 (2020).

18. Beniya, A. \& Higashi, S. Towards dense single-atom catalysts for future automotive applications. Nat. Catal. 2, 590-602 (2019).

19. Bai, B., Arandiyan, H. \& Li, J. Comparison of the performance for oxidation of formaldehyde on nano- $\mathrm{Co}_{3} \mathrm{O}_{4}, 2 \mathrm{D}-\mathrm{Co}_{3} \mathrm{O}_{4}$, and $3 \mathrm{D}-\mathrm{Co}_{3} \mathrm{O}_{4}$ catalysts. Appl. Catal. B 142-143, 677-683 (2013).

20. Ghosh, T. K. \& Nair, N. N. Rh1 $/ \gamma-\mathrm{Al}_{2} \mathrm{O}_{3}$ single-atom catalysis of $\mathrm{O}_{2}$ activation and $\mathrm{CO}$ oxidation: mechanism, effects of hydration, oxidation state, and cluster size. ChemCatChem 5, 1811-1821 (2013).

21. Zhang, C. J. \& Hu, P. Why must oxygen atoms be activated from hollow sites to bridge sites in catalytic CO oxidation? J. Am. Chem. Soc. 122, 2134-2135 (2000).

22. $\mathrm{Yu}$, Q. et al. Engineering an effective $\mathrm{MnO}_{2}$ catalyst from $\mathrm{LaMnO}_{3}$ for catalytic methane combustion. Fuel 239, 1240-1245 (2019).

23. Nelson, N. C., Nguyen, M.-T., Glezakou, V.-A., Rousseau, R. \& Szanyi, J. Carboxyl intermediate formation via an in situ-generated metastable active site during water-gas shift catalysis. Nat. Catal. 2, 916-924 (2019).

24. Gao, J. et al. Tuning chemical bonding of $\mathrm{MnO}_{2}$ through transition-metal doping for enhanced CO oxidation. J. Catal. 341, 82-90 (2016).

25. Qu, W. et al. Single-atom catalysts reveal the dinuclear characteristic of active sites in NO selective reduction with $\mathrm{NH}_{3}$. Nat. Commun. 11, 1532 (2020).

26. Zhang, B. et al. Stabilizing a platinum 1 single-atom catalyst on supported phosphomolybdic acid without compromising hydrogenation activity. Angew. Chem. Int. Ed. 55, 8319-8323 (2016).

27. Bae, W. K. et al. Highly effective surface passivation of PbSe quantum dots through reaction with molecular chlorine. J. Am. Chem. Soc. 134, 20160-20168 (2012). 
28. He, C. et al. Recent advances in the catalytic oxidation of volatile organic compounds: a review based on pollutant sorts and sources. Chem. Rev. 119, 4471-4568 (2019).

29. Dai, Q. et al. HCl-tolerant $\mathrm{H}_{\mathrm{x}} \mathrm{PO}_{4} / \mathrm{RuO}_{\mathrm{x}}-\mathrm{CeO}_{2}$ catalysts for extremely efficient catalytic elimination of chlorinated VOCs. Environ. Sci. Technol. 55, 4007-4016 (2021).

30. Xu, R., Wang, X., Wang, D., Zhou, K. \& Li, Y. Surface structure effects in nanocrystal $\mathrm{MnO}_{2}$ and $\mathrm{Ag} / \mathrm{MnO}_{2}$ catalytic oxidation of CO. J. Catal. 237, 426-430 (2006).

31. Zhang, Z. et al. Site-resolved $\mathrm{Cu}_{2} \mathrm{O}$ catalysis in the oxidation of CO. Angew Chem. Int. Ed. 58, 4276-4280 (2019).

32. Mao, Y. et al. Unravelling the synergy between oxygen vacancies and oxygen substitution in $\mathrm{BiO}_{2-\mathrm{x}}$ for efficient molecular-oxygen activation. Angew. Chem. Int. Ed. 59, 3685-3690 (2020).

33. Wang, L.-N. et al. Catalytic $\mathrm{CO}$ oxidation by $\mathrm{O}_{2}$ mediated by noble-metal-free cluster anions $\mathrm{Cu}_{2} \mathrm{VO}_{3-5}{ }^{-}$. Angew. Chem. Int. Ed. 57, 3349-3353 (2018).

34. Wei, X. et al. Geometrical structure of the gold-iron(III) oxide interfacial perimeter for CO oxidation. Angew. Chem. Int. Ed. 57, 11289-11293 (2018).

35. Rong, S., Zhang, P., Liu, F. \& Yang, Y. Engineering crystal facet of $\alpha-\mathrm{MnO}_{2}$ nanowire for highly efficient catalytic oxidation of carcinogenic airborne formaldehyde. ACS Catal. 8, 3435-3446 (2018).

36. Ravel, B. \& Newville, M. ATHENA, ARTEMIS, HEPHAESTUS: data analysis for X-ray absorption spectroscopy using IFEFFIT. J. Synchrotron Radiat. 12, 537-541 (2005).

37. Kresse, G. \& Furthmüller, J. Efficient iterative schemes for ab initio total-energy calculations using a plane-wave basis set. Phys. Rev. B 54, 11169-11186 (1996).

38. Kresse, G. \& Joubert, D. From ultrasoft pseudopotentials to the projector augmented-wave method. Phys. Rev. B 59, 1758-1775 (1999).

39. Perdew, J. P., Burke, K. \& Ernzerhof, M. Generalized gradient approximation made simple. Phys. Rev. Lett. 77, 3865-3868 (1996).

40. Lin, T. et al. Mesoporous $\mathrm{a}-\mathrm{MnO}_{2}$ microspheres with high specific surface area: controlled synthesis and catalytic activities. Chem. Eng. J. 286, 114-121 (2016).

41. Henkelman, G., Uberuaga, B. P. \& Jónsson, H. A climbing image nudged elastic band method for finding saddle points and minimum energy paths. $J$. Chem. Phys. 113, 9901-9904 (2000).

42. Henkelman, G. \& Jónsson, H. Improved tangent estimate in the nudged elastic band method for finding minimum energy paths and saddle points. J. Chem. Phys. 113, 9978-9985 (2000)

43. Kim, J. et al. Tailoring binding abilities by incorporating oxophilic transition metals on 3D nanostructured $\mathrm{Ni}$ arrays for accelerated alkaline hydrogen evolution reaction. J. Am. Chem. Soc. 143, 1399-1408 (2021).

\section{Acknowledgements}

We acknowledge the National Natural Science Foundation of China (21976066),

National Key Research and Development Program of China (2019YFC1806203), the
Fundamental Research Funds for the Central Universities (CCNU19QN065) for financial support.

\section{Author contributions}

H.Y.G. and X.L. conceived and synthesized the catalyst and completed most of the experiments and characterization. X.F.L. completed the electron microscopy test. C.C.L. helped with the catalytic performance test. K.W. and Y.B.G. performed $\mathrm{H}_{2}-\mathrm{TPR}$ and $\mathrm{O}_{2}-$ TPD tests. H.Y.G. and G.M.Z. carries out theoretical calculation and analysis. X.L. and L.Z.Z. designed and supervised the project. H.Y.G., X.L. and L.Z.Z. co-wrote the paper.

\section{Competing interests}

The authors declare no competing interests.

\section{Additional information}

Supplementary information The online version contains supplementary material available at https://doi.org/10.1038/s41467-021-25726-w.

Correspondence and requests for materials should be addressed to Xiao Liu or Lizhi Zhang.

Peer review information Nature Communications thanks the anonymous reviewers for their contribution to the peer review of this work. Peer reviewer reports are available.

Reprints and permission information is available at http://www.nature.com/reprints

Publisher's note Springer Nature remains neutral with regard to jurisdictional claims in published maps and institutional affiliations.

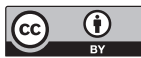

Open Access This article is licensed under a Creative Commons Attribution 4.0 International License, which permits use, sharing, adaptation, distribution and reproduction in any medium or format, as long as you give appropriate credit to the original author(s) and the source, provide a link to the Creative Commons license, and indicate if changes were made. The images or other third party material in this article are included in the article's Creative Commons license, unless indicated otherwise in a credit line to the material. If material is not included in the article's Creative Commons license and your intended use is not permitted by statutory regulation or exceeds the permitted use, you will need to obtain permission directly from the copyright holder. To view a copy of this license, visit http://creativecommons.org/ licenses/by/4.0/.

(C) The Author(s) 2021 